\title{
Analisis Daya Tampung Jaringan Jalan Tidak Sebidang (Studi Kasus: Flyover Teuku Umar, Kota Bandar Lampung)
}

\author{
Zenia F Saraswati*, Balqis Febriyantina Gunari \\ Program Studi Perencanaan Wilayah dan Kota, Institut Teknologi Sumatera \\ "Correspondence email: zenia.saraswati@pwk.itera.ac.id
}

\begin{abstract}
Abstrak. Kota Bandar Lampung sebagai ibukota Provinsi Lampung menyebabkan jumlah pergerakannya tinggi sehingga kemacetan lalu lintas tidak dapat dihindari pada beberapa ruas jalan di Kota Bandar Lampung. Menanggapi permasalahan tersebut, pemerintah Kota Bandar Lampung melakukan banyak pembangunan jalan layang (flyover) untuk sebagai upaya peningkatan kapasitas jalan untuk memenuhi kebutuhan yang tinggi dan diproyeksikan untuk terus meningkat. Flyover Teuku Umar di kecamatan Kedaton merupakan salah satu dari tiga jalan layang yang dibangun pada tahun 2017-2018. Jalan Teuku Umar memiliki kegiatan yang cukup beragam yaitu pusat kegiatan perdagangan, pendidikan, dan kesehatan. Penelitian ini dilakukan untuk mengetahui dampak yang ditimbulkan oleh pembangunan jalan layang terhadap performa lalu lintas baik di wilayah internal maupun eksternalnya menggunakan proyeksi VCR pada jalan yang terdampak. Penelitian ini juga mempertimbangkan penggunaan lahan di sekitar Proyeksi dilakukan menggunakan data Matriks Asal dan Tujuan, proyeksi jumlah penduduk, proyeksi kepemilikan kendaraan, serta kapasitas jalan. Hasil analisis penelitian menjelaskan bahwa batas waktu pelayanan jalan pada jalan eksisting/ underpass dan flyover tetap dengan arus stabil dengan VCR $<0.85$ adalah 15 . Namun kondisi ruas flyover tetap jenuh sehingga pemerintah di tahun 2033, menjadikan batasan intensitas bangunan penting dilakukan.
\end{abstract}

Kata kunci: jalan layang; manajemen lalu lintas; rasio kapasitas volume kendaraan

\begin{abstract}
The city of Bandar Lampung as the capital of Lampung Province causes a high number of movements so that traffic jams cannot be avoided on several roads in the City of Bandar Lampung. Responding to these problems, the city government of Bandar Lampung has carried out many flyovers as an effort to increase road capacity to meet high demand and is projected to continue to increase. The Teuku Umar flyover in Kedaton sub-district is one of the three flyovers built in 2017-2018. Jalan Teuku Umar has quite a variety of activities, namely the center of trade, education and health activities. This research was conducted to determine the impact caused by the construction of flyovers on traffic performance in both internal and external areas using a $V C R$ projection on the affected roads. This research also considers land use in the vicinity of the projection, which is carried out using the Origin and Destination Matrix data, population projections, vehicle ownership projections, and road capacity. The results of the research analysis explain that the time limit for road services on existing roads / underpasses and flyovers is still stable with a VCR $<0.85$ is 15 years. However, the condition of the flyover section remains saturated, so the government in 2033 makes it important to limit building intensity.
\end{abstract}

Keywords: flyover; traffic management; volume capacity ratio

\section{PENDAHULUAN}

Kemacetan lalu lintas merupakan permasalahan yang diakibatkan oleh kapasitas prasarana jalan di perkotaan tidak berimbang dengan jumlah kepemilikan kendaraan pribadi yang meningkat dengan laju pertumbuhan yang tinggi Dampak negatif yang ditimbulkan dari kemacetan lalu lintas adalah waktu perjalanan menjadi lebih lama sampai di tempat tujuan, konsumsi bahan bakar meningkat, alokasi anggaran belanja keluarga untuk membeli bahan bakar meningkat, kenyamanan perjalanan berkurang, dsb (Adisasmita, 2011).

Salah satu pendekatan dalam mengatasi kemacetan adalah melalui peningkatan kapasitas prasarana jalan, dalam bentuk pelebaran jalan yang sempit dan rusak, peningkatan daya dukung jalan, dan pembangunan jalan baru. Persimpangan jembatan layang adalah persimpangan yang memiliki jembatan khusus yang dibangun di atas tingkat persimpangan untuk memungkinkan aliran bebas dalam dua arah di salah satu jalan utama - untuk meningkatkan kapasitas arus lalu lintas dan mengurangi kemacetan lalu lintas di kedua arah ini, tetapi di bawah jembatan, itu signallisasi lalu lintas yang ada masih digunakan untuk mengontrol lalu lintas seperti situasi sebelumnya (Salatoom, 2015). Flyover hanya memfasilitasi arus lalu lintas ke arah jembatan, tetapi infrastruktur tidak dapat sepenuhnya menyelesaikan semua masalah terutama di jalan sekunder. Menurut sumber pendefinsian dalam Quora menjelaskan bahwa flyover adalah struktur yang menggabungkan dua atau lebih titik yang dipisahkan dengan aksesibilitas rute atau struktur dibuat untuk memotong lalu-lintas agar mempercepat dan memperlancar suatu perjalanan. Flyover biasanya dibuat di luar persimpangan jalan.

Kota Bandar Lampung sebagai ibukota Provinsi Lampung memiliki perkembangan penggunaan lahan yang sangat cepat. Tingkat pertumbuhan pendudukan di Kota Bandar Lampung adalah 1.08\%, pada tahun 2017 dengan jumlah pendudukan 1,015,910 jiwa. Disisi lain, 
luas lahan terbangun Kota Bandar Lampung 9,920 ha; masih terdapat hamparan lahan belum terbangun seluas 8,231 ha. Hal ini memberikan kesempatan pada sehingga ada potensi lahan di Kota Bandar Lampung akan terus berkembang. Perkembangan Kota Bandar Lampung yang tinggi menyebabkan jumlah pergerakannya tinggi pula. Hal ini membuat kemacetan lalu lintas tidak dapat dihindari pada beberapa ruas jalan di Kota Bandar Lampung.Data yang bersumber dari Dinas Perhubungan tahun 2010 mengenai besarnya bangkitan dan tarikan masyarakat di Kota Bandar Lampung tahun 2015 menjelaskan bahwa bangkitan sebesar 315.512 orang/hari dan besar tarikan pergerakan 160.320 orang/hari. Kota Bandar Lampung menjadi asal/tujuan perjalanan yang terbesar di Provinsi Lampung. Kota Bandar Lampung memikul $16,4 \%$ dan tarikan perjalanannya sebesar $8,3 \%$ dari seluruh pergerakan yang terjadi di Provinsi Lampung. Disisi lain, kepemilikan kendaraaan bermotor yang terus meningkat turut memperkeruh masalah kemacetan di Kota Bandar Lampung. Berdasarkan data BPS dan Dinas Perhubungan Kota Bandar Lampung, tingkat pertumbuhan kendaraan bermotor baik jenis kendaraan mobil pribadi maupun motor diperoleh sebesar $23 \%$ untuk tingkat pertumbuhan mobil pribadi (Light Vehichle) dan tingkat pertumbuhan motor (Motorcycle) sebesar 77\% pada tahun 2010. Menanggapi kondisi ini, Kota Bandar Lampung melakukan pembangunan jalan baru berupa jalan layang (flyover). Pada tahun 2017, pemerintah membangun Flyover Teuku Umar, Flyover Pramuka, dan Flyover Teuku Cik Ditiro untuk menyelesaikan permasalahan kemacetan. Pembangunan flyover selesai pada pertengahan Januari 2018.

Jalan Teuku Umar memiliki kegiatan yang cukup beragam yaitu pusat kegiatan perdagangan, pendidikan, dan kesehatan. Flyover Teuku Umar sebagai ruas jalan strategis, yang dilalui oleh jalan persimpangan arah Jalan Sultan Agung dan Jalan Pagar Alam. Flyover Teuku Umar dikatakan stategis karena jalan yang dilalui masyarakat dari Kabupaten Lampung Utara, Lampung Tengah, dan Lampung Timur untuk menuju pusat kegiatan di Kota Bandar Lampung.
Melalui keberadaan flyover ini, Pemerintah Kota Bandar Lampung berharap untuk dapat mengatasi kemacetan lalu lintas di beberapa ruas yang padat pada jam sibuk. Padahal keberadaan flyover hanya memberikan solusi sesaat dan hanya menangani permasalahan kemacetan pada bagian ruas sepanjang flyover saja. Disisi lain, permasalahan kemacetan pada ruas jalan lain tetap tidak teratasi. Menjadi penting untuk mengetahui dampak flyover secara menyeluruh tidak hanya pada ruas jalan yang terdampak secara langsung. Penelitian ini berusaha mengkaji pengaruh pembangunan flyover terhadap penurunan beban lalulintas termasuk VCR pada ruas Jalan Teuku Umar. Tujuan penelitian ini dilakukan adalah untuk melihat pengaruh pembangunan flyover terhadap penurunan beban lalu-lintas pada Jalan Teuku Umar.

\section{Wilayah Studi}

Wilayah studi penelitian adalah ruas Flyover Teuku Umar yang mana merupakan jalan dengan kelas jalan yang arteri sekunder. Jalan Teuku Umar memiliki lebar \pm 3.3 meter dan direncanakan untuk memiliki jalan layang membentang sepanjang 400 meter. Jalan Teuku Umar merupakan jalan 2 arah 4 lajur dengan. Berdasarkan data Dinas Perhubungan Kota Bandar Lampung, Jalan Teuku Umar memiliki Volume sebesar 2028 smp/jam dan kapasitas sebesar 2709 smp/jam menjadikan rasio volume dan kapasitas (VCR) sebesar 0.75 .

Flyover Teuku Umar berada di Kecamatan Kedaton memiliki Jalan Teuku Umar memiliki kegiatan yang cukup beragam yaitu pusat kegiatan perdagangan, pendidikan, dan kesehatan. Adapun dominasi fungsi bangunan di sepanjang Flyover Teuku Umar adalah bangunan perdagangan dan jasa, dengan dominasi jumlah lantai bangunan sebanyak 1 lantai hingga 3 lantai. Terdapat satu bangunan dengan fungsi bangunan sebagai fasilitas perdagangan dan jasa dengan 4 lantai. Detil penggunaan lahan di sepanjang Jalan Teuku Umar serta kegiatannya dapat terlihat pada Tabel 1.

Tabel 1. Dominasi Jenis Kegiatan di Jalan Teuku Umar

\begin{tabular}{lllc}
\hline \multicolumn{1}{c}{ Fungsi Bangunan } & $\begin{array}{c}\text { Jumlah Lantai Bangunan } \\
\text { (lantai) }\end{array}$ & \multicolumn{1}{c}{ Fungsi Bangunan } & $\begin{array}{c}\text { Jumlah Lantai } \\
\text { Bangunan (lantai) }\end{array}$ \\
\hline Kanan & & & Kiri \\
\hline Komersil (ruko deret tiga) & 3 & Komersil (ruko tiga deret) & 1 \\
Komersil (satu bangunan) & 3 & Fasilitas Kesehatan (puskesmas) & 2 \\
Komersil (satu bangunan) & 1 & Persimpangan & 3 \\
Fasilitas Pendidikan Dasar & 1 & Komersil (ruko 10 deret) & 1 \\
Komersil (satu bangunan) & 2 & Komersil (pom bensin) & 3 \\
Komersil (satu bangunan) & 2 & Komersil (tempat les) & 3 \\
Rumah (1 & 1 & Dua bangunan rumah & 1 \\
Komersil (satu bangunan) & 1 & Komersil (ruko 6 deret) & 3 \\
Persimpangan & 4 & Fasilitas Pendidikan Tinggi & - \\
Komersil (mall) & 4 &
\end{tabular}


Zenia F Saraswati dan Balqis Febriyantina Gunari, Analisis Daya Tampung Jaringan Jalan Tidak Sebidang (Studi Kasus: Flyover Teuku Umar, Kota Bandar Lampung)

Komersil (satu bangunan)

Komersil (satu bangunan)

Komersil (satu bangunan)

Komersil (ruko)

Komersil

Komersil (ruko deret dua)

Komersil (ruko)

Komersil (satu bangunan)

Komersil (satu bangunan)

Komersil (ruko deret dua)

Komersil (satu bangunan)

Perkantoran

Komersil (ruko 11 deret)

Sumber: Hasil Google Street View, 2018

Gambar 1 menunjukkan kondisi ruas Jalan Teuku Umar setelah adanya pembangunan flyover Teuku Umar. Kapasitas jalan eksisting/underpass akan lebih terbatas pergerakan kendaraan dan kendaraan yang menggunakan flyover pada akhirnya akan bersama-sama menggunakan jalan eksisting/ underpass. Jalan eksisting/underpass diperuntukkan bagi kendaraan-kendaraan yang ingin menuju kegiatan yang berada di bawah flyover. Adapun secara kewilayahan, lokasi Jalan Teuku Umar merupakan Bagian Wilayah Kota (BWK) A yang merupakan wilayah pelayanan kota yang bertindak sebagai Central Business District (CBD) dari Kota Bandar Lampung. Pada Gambar 2 lokasi Flyover Teuku Umar dapat terlihat sebagai titik dengan warna kuning.

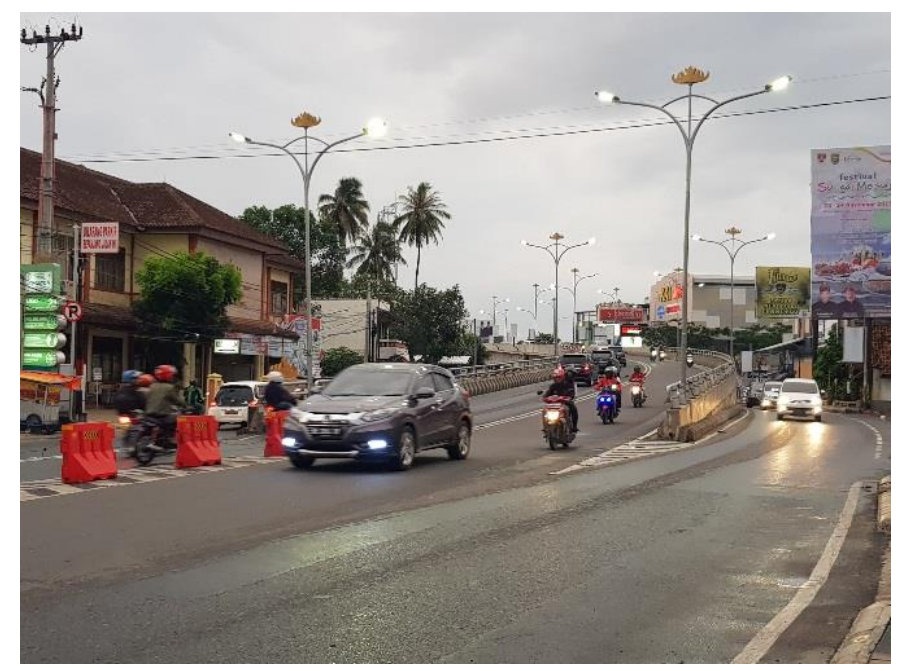

Gambar 1. Kondisi Saat Adanya Pembangunan Flyover Teuku Umar

Sumber: Dokumentasi Pribadi, 2019
Komersil (bangunan rumah makan 6 deret)

Komersil (satu bangunan) 1

Komersil (ruko 6 deret) 3

Komersil (ruko empat deret) 2

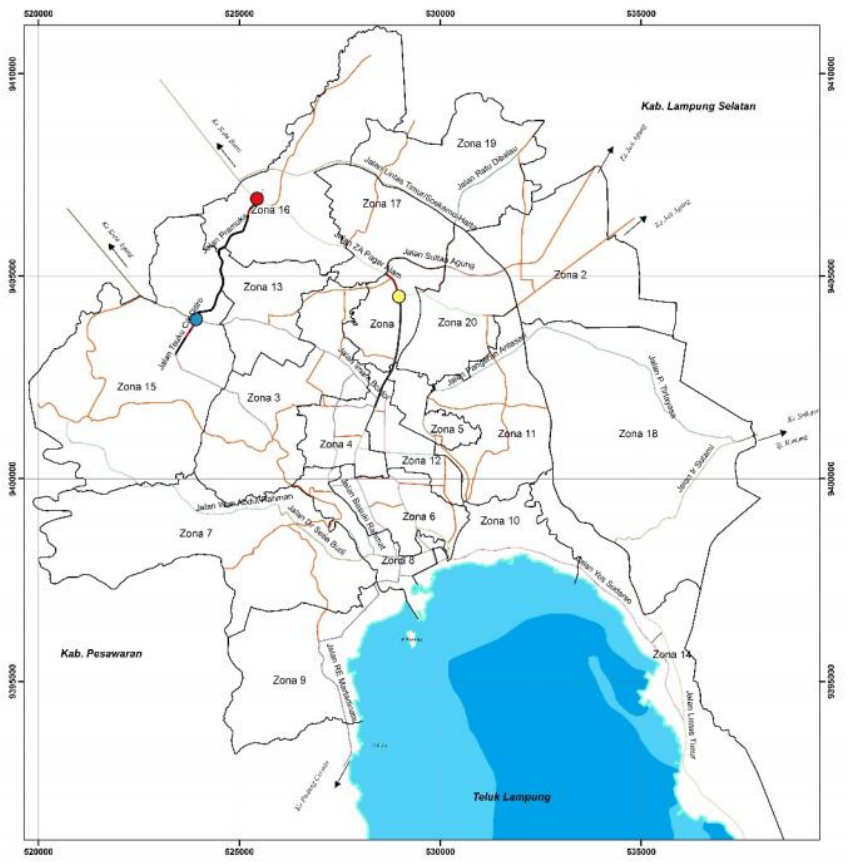

Gambar 2. Peta Wilayah Studi

Sumber: Hasil Analisis, 2019

\section{METODE}

Pada penelitian ini, pengumpulan data dilakukan pada Bulan Juli 2019 dilakukan melalui survei ke instansi terkait dan sesuai dengan pemenuhan kebutuhan data guna dilakukannya analisis penelitian. Instansiinstansi yang menjadi sumber data yakni Dinas Perhubungan Kota Bandar Lampung, Badan Perencanaan dan Pembangunan Daerah (Bappeda) Kota Bandar Lampung, Dinas Pekerjaan Umum Kota Bandar Lampung, dan Dinas Perumahan dan Permukiman Kota Bandar Lampung.

Selanjutnya analisis dilakukan melalui proyeksi volume lalu-lintas berdasarkan data matriks asal-tujuan (MAT) Kota Bandar Lampung. Analisis ini dilakukan menggunakan metode furness (Tamin, 2000). Sebelumnya dilakukan terlebih dahulu proyeksi jumlah kendaraan bermotor di Kota Bandar Lampung untuk mengetahui besaran tingkat pertumbuhan kendaraan bermotor di Kota Bandar Lampung dengan metode 
eksponensial. Proyeksi ini kemudian menjadi dasar melakukan proyeksi volume kendaraan pada jam puncak.

Besaran total volume kendaraan pada didasarkan pada jumlah volume kendaraan pada jam puncak pasangan asal-tujuan. Konversi satuan data MAT dari orang/hari menjadi smp/jam telah dijelaskan di atas dan tahapan selanjutnya adalah melakukan proyeksi volume kendaraan berdasarkan tabel matriks asal-tujuan Kota Bandar Lampung, dengan data awal yang dimiliki adalah data matriks asal-tujuan Kota Bandar Lampung tahun 2013.

Tabel 2. Jumlah Kendaraan Bermotor di Kota Bandar Lampung Tahun 2005-2009

\begin{tabular}{cccc}
\hline Tahun & Mobil Pribadi & Motor & Jumlah \\
\hline 2005 & 40,560 & 121,682 & 162,242 \\
2006 & 50,380 & 150,930 & 201,310 \\
2007 & 62,583 & 190,822 & 253,405 \\
2008 & 74,300 & 250,065 & 324,365 \\
2009 & 96,573 & 327,180 & 423,753 \\
\hline
\end{tabular}

Sumber: BPS dan Dinas Perhubungan Kota Bandar Lampung, 2010

Dasar Perhitungan Konversi Satuan Data MAT adalah peraturan mengenai besaran persentase jumlah kendaraan bermotor pada jam puncak dalam satu hari (9$10 \%$ dari total volume harian yang bersumber dari LTDP tahun 1992, dan prinsip konversi lainnya bersumber dari Buku Manual Kapasitas Jalan Indonesia Tahun 1997 mengenai faktor pengali untuk LV (kendaraan ringan) sebesar 1 dan MC (motor) sebesar 0.4 berdasarkan emp (Ekivalensi Mobil Penumpang) tipe pendekat (terlawan) menurut MKJI. Prinsip lainnya yaitu perbandingan banyaknya jumlah kendaraan bermotor dengan terbagi mobil pribadi (LV) dan motor (MC). Persentase perbandingan antara jumlah mobil dan motor didasarkan atas rasio perbandingan total kendaraan bermotor di Kota Bandar Lampung tahun terakhir yaitu tahun 2009 terhadap masing-masing jumlah mobil atau motor pada tahun 2009.

Proyeksi data MAT digunakan metode furness berdasarkan trend pertumbuhan kendaraan bermotor di Kota Bandar Lampung. Rasio pertumbuhan adalah 1.76 untuk nilai tingkat pertumbuhan yang tertinggi dan rentang yang digunakan sebagai nilai $\mathrm{E}$ (dalam metode furness) dibagi dengan tiga rentang sehingga berdasarkan kecamatan dengan jumlah penduduk terbanyak akan memiliki nilai $\mathrm{E}=1.76$ sedangkan rentang yang kedua dengan nilai $\mathrm{E}=1.17$ dan rentang pertama dengan jumlah penduduk paling sedikit diantara yang lain dengan nilai $\mathrm{E}=0.59$. Hasil dari proyeksi tingkat pertumbuhan serta MAT dapat terlihat pada Lampiran.

Tahapan selanjutnya adalah melakukan metode sensitivitas untuk mengetahui perubahan volume lalulintas, Volume Capacity Rasio (VCR) melalui pengurangan beban lalu-lintas secara bertahap pada jalan eksisting/ jalan underpass setelah dibangunnya flyover. Prinsip yang digunakan dalam melakukan metode sensitivitas adalah besaran persentase pengurangan beban lalu-lintas pada jalan eksisting dan sisa volume lalu-lintas tersebut akan berpindah pada bangunan jalan baru yang merupakan Flyover. Persentase yang digunakan dimulai dari nilai persentase yang paling minimum 10\% hingga $90 \%$ hingga nantinya dengan menggunakan prinsip keseimbangan Wardrop yang termasuk ke dalam salah satu prinsip dalam trip assignment (pembebanan lalu-lintas). Namun prinsip keseimbangan Wardrop yang digunakan dalam penelitian ini tidak secara utuh digunakan karena tidak adanya unsur faktor pemilihan rute. Pada analisis ini, menggunakan dua pilihan jalan yang terpilih yaitu jalan eksisting/ jalan underpass dan flyover. Adapun nilai kapasitas tambahan yang diberikan oleh flyover yang digunakan dalam penelitian ini dapat terlihat pada Tabel 3.

Tabel 3. Hasil Perhitungan Penambahan Kapasitas oleh Flyover di Kota Bandar Lampung

\begin{tabular}{ll}
\hline Faktor Perhitungan Kapasitas Flyover & Nilai (smp/jam) \\
\hline ( $\left._{0}\right)$ Kapasitas Dasar & 2,900 \\
jenis Flyover yang diteliti adalah jalan 2 jalur tanpa pembatas dengan total 2 arah & 1.29 \\
(FC $\mathrm{F}_{\mathrm{W}}$ ) Faktor penyesuaian lebar jalur lalu lintas & 1 \\
(FC $\mathrm{SP})$ Faktor penyesuaian pemisah arah & Flyover tidak ada hambatan samping \\
(FC $\mathrm{SF}$ ) Faktor penyesuaian hambatan samping & 1 \\
(FCcs)=Faktor penyesuaian ukuran kota & \\
Jumlah penduduk tahun 2017 di Kota Bandar Lampung sebanyak 1,015,910 jiwa & $\mathbf{3 , 7 4 1}$ \\
(C) Kapasitas &
\end{tabular}

Sumber: Hasil Analisis, 2019

\section{HASIL DAN PEMBAHASAN}

Rasio pertumbuhan penduduk di Kota Bandar Lampung hingga tahun 2017 adalah 1.08 sedangkan rasio pertumbuhan kendaraan bermotor pada tahun 2009 adalah 2.6. Rasio pertumbuhan yang lebih tinggi untuk kendaraan bermotor walaupun pertumbuhan kendaraan bermotor yang terjadi pada tahun 2009, jauh dari rasio pertumbuhan jumlah penduduk di Kota Bandar Lampung yang lebih terkini, dengan selisih 8 tahun namun rasio pertumbuhan kendaraan bermotor jauh lebih signifikan dibandingkan jumlah penduduk. Penduduk dengan pendapatan menengah ke atas 
memiliki indikasi secara trend pertumbuhan kendaraan bermotor akan mempunyai lebih dari dua kendaraan bermotor.

Pada Tabel 4 bagian yang bertanda biru menunjukkan bahwa saat 15-20 tahun ke depan (20332038) di prediksi kepemilikan kendaraan bermotor telah sangat tinggi untuk tiap penduduknya berdasarkan kaitannya dengan jumlah penduduk asli yang tinggal dan terhitung oleh sensus penduduk sebagai masyarakat Kota Bandar Lampung. Hal yang mungkin terjadi adalah ada kemungkinan sejumlah kepemilikan kendaraan bermotor yang tidak tercatat sehingga hasil perhitungan prediksi peningkatan jumlah kendaraan bermotor yang terjadi secara signifikan berdasarkan standar metode perhitungan dengan laju pertumbuhan kendaraan pada tahun eksisting (pada tahun 2005-2009).

Tabel 4. Jumlah Penduduk dan Jumlah Kendaraan Bermotor

\begin{tabular}{cccc}
\hline Tahun & $\begin{array}{c}\text { Jumlah } \\
\text { Penduduk }\end{array}$ & $\begin{array}{c}\text { Jumlah } \\
\text { Kendaraan } \\
\text { Bermotor }\end{array}$ & $\begin{array}{c}\text { Rasio Jumlah } \\
\text { Kendaraan } \\
\text { Bermotor \& } \\
\text { Jumlah Penduduk }\end{array}$ \\
\hline 2018 & $1,026,051$ & $1,174,964$ & 1 \\
2023 & $1,078,293$ & $2,070,555$ & 2 \\
2028 & $1,133,195$ & $3,648,790$ & 3 \\
2033 & $1,190,893$ & $6,430,000$ & 5 \\
2038 & $1,251,529$ & $11,331,127$ & 9 \\
\hline
\end{tabular}

Sumber: Hasil Analisis, 2019

Peningkatan jumlah kendaraan bermotor ini di tiap pulaunya ini menunjukkan keseuaian model dengan data bahwa jumlah kendaraan bermotor paling tinggi terjadi pada tahun 2018 di Pulau Jawa sebesar 62.81\%, diikuti oleh Pulau Sumatera sebesar 21.44\%. Berikut jumlah kendaraan bermotor untuk tiap provinsi di Indonesia pada tahun 2018 (Paryadi, 2018).

Tabel hasil proyeksi MAT yang kemudian dikonversikan dalam satuan smp/jam yang kemudian dibandingkan dengan kapasitas eksisting menghasilkan proyeksi nilai VCR dari jalan eksisting tanpa flyover. Dapat terlihat pada Tabel 4, berdasarkan proyeksi MAT tahun 2038 dapat terlihat bahwa volume kendaraan tiap jam puncak di Kecamatan Kedaton (adanya Flyover Teuku Umar) memiliki total volume sebesar 14,646 smp/jam puncak.

Tabel 5. Total Volume Lalu-lintas dan Kondisi VCR Jalan Teuku Umar Tahun 2018-2038

\begin{tabular}{ccc}
\hline Tahun & Volume (smp/jam puncak) & VCR \\
\hline 2018 & 1,525 & 0.56 \\
2023 & 2,697 & 0.99 \\
2028 & 4,757 & 1.76 \\
2033 & 8,379 & 3.09 \\
2038 & 14,646 & 5.41 \\
\hline
\end{tabular}

Sumber: Hasil Analisis, 2019

Kondisi VCR $\geq 1$ dan VCR $\geq 0.85$ (volume lalulintas melebihi kapasitas jalan) berdasarkan ketentuan
MKJI tahun 1997 menjelaskan bahwa hal tersebut tidak mungkin terjadi karena sikap pengendara yang akan menghindari kemacetan lalu-lintas dan selalui memilih rute perjalanan dengan minimum cost.

Pada grafik di bawah juga untuk garis yang berwarna merah menunjukkan kondisi volume lalu-lintas yang melebihi kapasitas sehingga pada waktu jenuh kapasitas ruas jalan harus ditingkatkan. Peningkatan kapasitas jalan harus dilakukan dengan batas minimum VCR jalan arteri sekunder adalah 0.8 atau $\leq 0.85$. Pada grafik menjelaskan bahwa pada tahun 2023 Jalan Teuku Umar akan jenuh.

Antisipasi Pemerintah Kota Bandar Lampung diharapkan tersedianya program baru untuk mencegah terjadinya kepadatan lalu-lintas di tiga lokasi keberadaan flyover yang dibangun pada tahun 2017 dan beroperasi pada tahun 2018. Jalan eksisting Teuku Umar dengan VCR 0.76 namun nilai VCR dengan tingkat pelayanan C sebagai tingkat pelayanan minimal pada jalan arteri sekunder, sehingga pada tahun 2028 Flyover Teuku Umar belum dikatakan sangat jenuh. Kondisi VCR jalan eksisting Teuku Umar pada tahun 2028 yaitu 0.70 dengan tingkat pelayanan B. Perbandingan peningkatan volume pada Jalan Teuku Umar dapat terlihat pada Gambar 3.

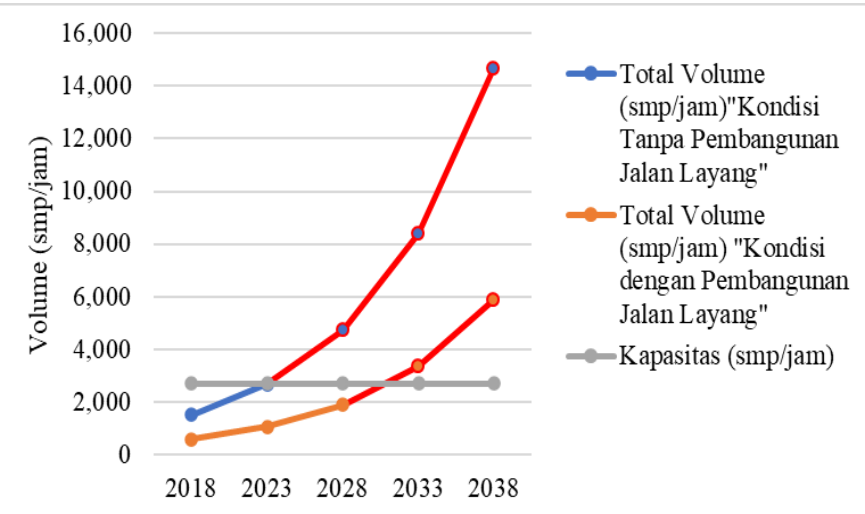

Gambar 3. Kondisi Perubahan Besaran Volume Lalu-lintas pada jalan eksisting dengan atau Tanpa Pembangunan Flyover Pada Jalan Teuku Umar

Sumber: Hasil Analisis, 2019

\section{Pembahasan}

Pembangunan flyover akan mempengaruhi fungsi kegiatannya, dan hal ini berkaitan dengan kondisi struktur ruang suatu perkotaan. Rencana struktur ruang perkotaan terdiri dari pusat sebagai CBD dan sub-pusat pelayanan. Pusat pelayanan diartikan sebagai pusat pelayanan primer, dengan diarahkan sebagai pusat kegiatan perdagangan dan jasa atau dikenal sebagai CBD. Sub-pusat pelayanan sebagai pusat pelayanan sekunder, fungsi pelayanannya di bawah CBD. Pusat pelayanan primer dan pusat pelayanan sekunder dibedakan berdasarkan cakupan wilayah pelayanannya. Pusat pelayanan primer sebagai CBD dengan jangkauan pelayanan seluruh wilayah kota dan provinsi sedangkan 
pusat pelayanan sekunder dengan jangkauan pelayanan untuk wilayah kota saja.

Ketetapan intensitas bangunan di sepanjang Jalan Teuku Umar khusus untuk pembangunan perbelanjaan modern pada tahun 2033 harus ditetapkan aturan baru untuk membatasi jumlah lantai bangunan perbelanjaan modern Mall Bumi Kedaton menjadi $\leq 7$ lantai dan harus menyertakan syarat untuk developer agar dalam melakukan penambahan lantai bangunan diharapkan terdapat charge dari pemerintah. Charge tersebut adalah seperti kompensasi oleh developer untuk misalnya menyediakan perluasan lahan parkir mall atau penyediaan lahan parkir di bawah tanah, dsb. Selain bangunan komersil mall, di sepanjang Jalan Teuku Umar juga terdapat deret ruko dengan jumlah lantai terbanyak di dominasi dengan 3 lantai.

Berdasarkan ketetapan dalam RTRW Kota Bandar Lampung Tahun 2010-2030 menjelaskan KLB maksimum 2.00 dengan jumlah lantai maksimum adalah 4 lantai. Jika dihitung $50 \%$ dari total volume di ruas Jalan Teuku Umar pada tahun 2033 (waktu jenuh flyover $\&$ jalan eksisting) yaitu sebesar 4,190 smp/jam puncak disebabkan oleh bangkitan dan tarikan di wilayah internal (dominasi bangunan yang terdapat di sepanjang flyover). Jika dihitung nilai VCR 4,190 smp/jam puncak dibandingkan terhadap kapasitas jalan eksisting Teuku Umar (2,709) maka nilai VCR pada tahun 2033 adalah 1.55 dengan tingkat pelayanan jalan $\mathrm{F}$.

Namun kondisi pelayanan jalan akan lebih baik, dengan mengurangi volume pada jalan eksisting/underpass Teuku Umar sebanyak $80 \%$ sehingga akan diperoleh besaran volume di jalan eksisting sebesar 1,676 smp/jam dan VCR 0.62 (tingkat pelayanan B). Hal yang terjadi pada kondisi flyover tahun 2033 memiliki volume sebesar 6,703 dan VCR 1.79 (tingkat pelayanan F).

Untuk mengantisipasi jenuhnya flyover dan jalan eksisting Teuku Umar memiliki cara yang berbeda, untuk meningkatkan layanan jalan eksisting/underpass Teuku Umar dengan mengurangi/ mengalihkan volume lalu-lintas di jalan eksisting sebanyak $80 \%$ dari total volume pada wilayah kecamatan terdampak yang telah dibebankan pada ruas jalan tersebut. Pengurangan/pengalihan besaran volume di jalan eksisting bisa dilakukan dengan membatasi intensitas bangunan di wilayah internal, yang berdasarkan kasus dalam penelitian ini bahwa dominasi fungsi bangunan di wilayah internal (adanya lokasi keberadaan pembangunan flyover) adalah bangunan perdagangan dan jasa.

\section{SIMPULAN}

Hasil analisis penelitian menjelaskan bahwa batas waktu pelayanan jalan pada jalan eksisting/ underpass dan flyover tetap dengan arus stabil hingga 2033 Sebelum jalan eksisting/underpass dan flyover mencapai titik jenuhnya maka penting untuk mengantisipasi melalui batasan intensitas bangunan di wilayah internal (lokasi keberadaan flyover). Sebelum jalan eksisting/underpass dan flyover mencapai titik jenuhnya maka penting untuk mengantisipasi melalui batasan intensitas bangunan di wilayah internal (lokasi keberadaan flyover).

\section{DAFTAR PUSTAKA}

Adisasmita, R. (2011). Manajemen Transportasi Darat. Yogyakarta: Graha Ilmu.

BPS Kota Bandung, (https://bandungkota.bps.go.id). Diakses pada tanggal 06 Februari 2019

Directorate Jenderal Bina Marga dan Directorate of Urban Road Development. (1996). Buku Highway Capacity Manual Project (HCM). Jakarta Selatan: PT. Bina Karya Persero.

Jumlah Kendaraan di Indonesia, (https://paryadi.com/2018/01/16/jumlah-

kendaraan-2018/). Diakses pada tanggal 06 Februari 2019.

Peraturan Menteri Perhubungan No. KM 14 Tahun 2006 Tentang Manajemen dan Rekayasa Lalu-lintas di Jalan.

Peraturan Menteri Perhubungan No. Km. 49 Tahun 2005 Tentang Sistem Transportasi Nasional.

Salatoom, N, P, T. (2015). A Study of Flyover-BridgeImproved Intersection. Prince of Songkla University, Engineering Journal Volume 19 Issue 1 Published 30 Januari 2015

Tamin, Ofyar Z. (2000). Perencanaan dan Pemodelan Transportasi (Edisi 2). Bandung: ITB. 